\title{
A lack of association between the IKZF2 rs12619285 polymorphism and coronary heart disease
}

\author{
HUADAN YE ${ }^{1}$, QINGXIAO HONG ${ }^{1}$, YIRUN LI $^{1}$, XUTING XU $^{1}$, YI HUANG ${ }^{2}$, \\ LIMIN XU $^{1}$, ANNAN ZHOU ${ }^{1}$, YOUPING DENG ${ }^{3}$ and SHIWEI DUAN ${ }^{1}$
}

\begin{abstract}
${ }^{1}$ Zhejiang Provincial Key Laboratory of Pathophysiology, School of Medicine, Ningbo University, Ningbo, Zhejiang 315211;
${ }^{2}$ Department of Neurosurgery, Ningbo First Hospital, Ningbo, Zhejiang 315010, P.R. China; ${ }^{3}$ Rush University Cancer Center, and Department of Internal Medicine and Biochemistry, Rush University Medical Center, Chicago, IL 60612, USA
\end{abstract}

Received April 8, 2014; Accepted January 5, 2015

DOI: $10.3892 /$ etm.2015.2282

\begin{abstract}
The IKZF2 rs12619285 polymorphism is associated with the eosinophil count, which has multidimensional functions in the pathogenesis of coronary heart disease (CHD). The aim of the present study was to investigate the contribution of the IKZF2 rs12619285 polymorphism to the risk of CHD in a Han Chinese population. In total, $721 \mathrm{CHD}$ cases and 631 non-CHD controls were recruited for an association study of the $I K Z F 2$ rs12619285 polymorphism. Genotyping was performed using the melting temperature-shift polymerase chain reaction method. No statistically significant association was observed between the IKZF2 rs12619285 polymorphism and CHD (odds ratio, $1.139,95 \%$ confidence interval, $0.927-1.334 ; \mathrm{P}=0.17)$. In addition, subgroup analyses by gender or age were unable to identify any association between IKZF2 rs12619285 and CHD ( $P>0.05)$, and there was no significant correlation between IKZF2 rs12619285 and the severity of CHD ( $>0.05)$. The power of the case-control study was determined to be $63.3 \%$. In addition, the $\mathrm{G}$ allele frequency was calculated as $63.6 \%$ in the Han Chinese population, which was similar to the $59.3 \%$ recorded for the HapMap Chinese population of Han Chinese individuals living in Beijing, compared with $24.3 \%$ in European descendents (HapMap-CEU). Therefore, the results indicated that the $I K Z F 2$ rs12619285 polymorphism was not associated with CHD in a Han Chinese population. The discrepancy in the association between rs12619285 and CHD
\end{abstract}

Correspondence to: Dr Youping Deng, Rush University Cancer Center, and Department of Internal Medicine and Biochemistry, Rush University Medical Center, 2150 W Harrison Street, Chicago, IL 60612, USA

E-mail: youpingd@gmail.com

Dr Shiwei Duan, Zhejiang Provincial Key Laboratory of Pathophysiology, School of Medicine, Ningbo University, 818 Fenghua Road, Ningbo, Zhejiang 315211, P.R. China

E-mail: duanshiwei@nbu.edu.cn

Key words: IKZF2, rs12619285, coronary heart disease, polymorphism may be due to the ethnic differences between Han Chinese and European populations.

\section{Introduction}

Coronary heart disease (CHD) is a major cause of mortality and disability worldwide (1). The global number of CHD-induced mortalities is increasing rapidly and is hypothesized to reach 23.3 million by 2030 (2). CHD is induced by the accumulation of plaques on vascular endothelial surfaces $(3,4)$. As a complex disease, CHD is influenced by lifestyle, environmental and genetic factors $(1,5)$. Twin studies have provided evidence that genetic and environmental factors play key roles in the occurrence and development of CHD (6-8).

The $I K Z F 2$ gene is located on chromosome $2 \mathrm{q} 13$ and encodes the zinc-finger protein, Helios, which is a member of the Ikaros family of zinc-finger proteins. IKZF2 protein is a functional component in lymphocyte differentiation (9) and plays a key role in the growth of the early hematopoietic system (10). Hematopoietic progenitors can develop into neutrophils, eosinophils, dendritic cells, Langerhans cells, macrophages and osteoclasts (11). Infiltration of eosinophils has been found in the myocardial tissue of patients with hypereosinophilic syndrome (12). The rs12619285 polymorphism of the $I K Z F 2$ gene has been associated with a variation in the blood eosinophil count (13). Furthermore, genes that are involved in the regulation of eosinophil numbers have been shown to be involved in the inflammatory regulation and immune responses that occur during the development of CHD (14-16). Eosinophils, as a type of white blood cell, exert multidimensional functions in the occurrence and development of autoimmune diseases (17), particularly in the pathogenesis of CHD $(18,19)$ by promoting thrombus formation (20).

In addition, a previous study found that the $I K Z F 2$ rs12619285 (G/A) polymorphism in European populations ( $\mathrm{G}$ allele frequency, 26\%; $\mathrm{P}=5.4 \times 10^{-10}$ ) and East Asian populations ( $\mathrm{G}$ allele frequency, 64\%; $\mathrm{P}=0.017$ ) was significantly associated with CHD (21), although there were large allele differences between the European and East Asian populations. Previously, preliminary results indicated that there was an association between IKZF2 rs12619285 and CHD 
Table I. Distribution of genotypes and alleles in the case and control subjects.

\begin{tabular}{lccccccccc}
\hline Genotype & $\begin{array}{c}\text { Controls } \\
(\mathrm{n}=631)\end{array}$ & $\begin{array}{c}\text { Single } \\
\text { vessel } \\
(\mathrm{n}=352)\end{array}$ & $\begin{array}{c}\text { Double } \\
\text { vessels } \\
(\mathrm{n}=168)\end{array}$ & $\begin{array}{c}\text { Triple } \\
\text { vessels } \\
(\mathrm{n}=201)\end{array}$ & $\begin{array}{c}\text { Total } \\
\text { cases } \\
(\mathrm{n}=721)\end{array}$ & $\chi^{2}$ & $\begin{array}{c}\text { P-value } \\
(\mathrm{df}=2)\end{array}$ & $\begin{array}{c}\text { P-value } \\
(\mathrm{df}=1)\end{array}$ & $\begin{array}{c}\text { OR } \\
(95 \% \mathrm{CI})\end{array}$ \\
\hline AA & 84 & 45 & 11 & 17 & 73 & & & & \\
AG & 291 & 156 & 79 & 101 & 336 & & & & \\
GG & 256 & 151 & 78 & 83 & 312 & 3.546 & 0.17 & 0.109 & $1.139(0.972-1.334)$ \\
\hline
\end{tabular}

OR, odds ratio; CI, confidence interval; df, degree of freedom.

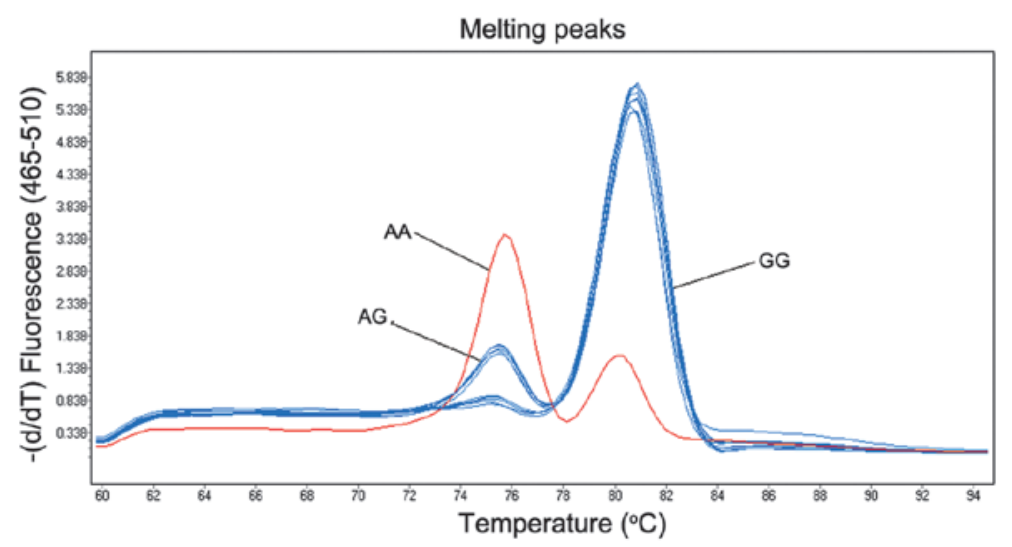

Figure 1. Detection of the three genotypes. The line marked AA indicated homozygous for allele A; the line marked AG indicated heterozygous; and the line marked GG indicated homozygous for allele G.

in the Chinese Han population [G allele frequency, $62.8 \%$; $\mathrm{P}=0.07$; odds ratio (OR), $1.38,95 \%$ confidence interval $(\mathrm{CI})$, 0.97-1.98], with no departure from the Hardy-Weinberg equilibrium (HWE) in the controls (22). Thus, an association was observed between IKZF2 rs12619285 and CHD (162 cases and 113 controls); however, the statistical power was only $45.2 \%$ (22). The small sample size used in this preliminary study may have been unable to indicate the authentic association between rs12619285 and CHD (22). Thus, the aim of the present study was to investigate the association between the rs12619285 polymorphism of the IKZF2 gene in CHD patients and non-CHD controls using an increased sample size.

\section{Materials and methods}

Sample collection. In total, 1,352 samples were collected between September 2011 and July 2013 in Ningbo Lihuili Hospital (Ningbo, China) and Ningbo Yinzhou People's Hospital (Ningbo, China). CHD cases were confirmed with angiographic evidence that showed vascular stenosis of $>50 \%$ in at least one major coronary artery. In addition, participants with a history of angioplasty or coronary artery bypass surgeries were classified as CHD cases. Control samples comprised patients whose vascular stenosis was $<50 \%$ in each of the major coronary arteries (23). The severity of CHD was classified according to the number of major coronary arteries affected by $>50 \%$ stenosis (single, double and triple). All the participants were unrelated and of Han Chinese origin, habituating in Zhejiang province.
Patients were excluded from the study if they suffered from congenital heart disease, cancer and severe liver or kidney diseases. All the blood samples were collected by the same investigator. This study was approved by the Ethical Committees of Ningbo Lihuili Hospital and Ningbo Yinzhou People's Hospital. All the individuals provided written informed consent.

Single nucleotide polymorphism genotyping. Genomic DNA from the peripheral blood was extracted using a nucleic acid automatic extractor (Lab-Aid 820; Zeesan Biotech Co., Ltd., Xiamen, China) and all the DNA samples were stored in Tris-EDTA buffer. Genotyping was performed using the melting temperature-shift polymerase chain reaction (PCR) method $(24,25)$. The Tm-shift PCR approach was used to differentiate the two allele-specific PCR products that were amplified using two forward primers and one common reverse primer. The two forward primers comprised one long and one short primer to generate two PCR products with different Tm values. The primers used were as follows: IKZF2-g forward, 5'-GCGGGCAGGGCGGCA CCAAGGAAAATGGAGCTTCTG-3'; IKZF2-a forward, 5'-GATTACCGACCAAGGAAAATGGAGCTTCTA-3'); and IKZF 2 reverse, 5'-GCCTCTTTAGGTAGGGAAGAG AGAACACA-3'. The PCR amplification program consisted of an initial denaturation at $95^{\circ} \mathrm{C}$ for $30 \mathrm{sec}$, followed by denaturation at $95^{\circ} \mathrm{C}$ for $30 \mathrm{sec}$, annealing at $59^{\circ} \mathrm{C}$ for $30 \mathrm{sec}$ and extension at $72^{\circ} \mathrm{C}$ for $30 \mathrm{sec}$ for 40 cycles, and a final extension at $72^{\circ} \mathrm{C}$ for $30 \mathrm{sec}$. PCR was performed using the ABI GeneAmp ${ }^{\circledR}$ PCR System 9700 with the 96-Well Sample Block 
Table II. Distribution of genotypes and alleles according to gender.

\begin{tabular}{|c|c|c|c|c|c|c|c|c|c|c|c|}
\hline \multirow[b]{2}{*}{ Gender } & \multicolumn{3}{|c|}{ Genotype (n) } & \multirow[b]{2}{*}{$\chi^{2}$} & \multirow{2}{*}{$\begin{array}{c}\text { P-value } \\
(\mathrm{df}=2)\end{array}$} & \multirow[b]{2}{*}{ HWE } & \multicolumn{2}{|c|}{ Allele (n) } & \multirow[b]{2}{*}{$\chi^{2}$} & \multirow{2}{*}{$\begin{array}{c}\text { P-value } \\
(\mathrm{df}=1)\end{array}$} & \multirow[b]{2}{*}{ OR $(95 \% \mathrm{CI})$} \\
\hline & GG & $\mathrm{AG}$ & AA & & & & G & A & & & \\
\hline \multicolumn{12}{|l|}{ Male } \\
\hline Cases $(n=516)$ & 217 & 242 & 57 & & & 0.441 & 676 & 356 & & & \\
\hline Controls $(n=345)$ & 140 & 157 & 48 & 1.588 & 0.452 & 0.730 & 437 & 253 & 0.852 & 0.356 & $1.099(0.899-1.344)$ \\
\hline \multicolumn{12}{|l|}{ Female } \\
\hline Cases $(n=205)$ & 95 & 94 & 16 & & & 0.326 & 284 & 126 & & & \\
\hline Controls $(n=286)$ & 116 & 134 & 36 & 3.534 & 0.171 & 0.898 & 366 & 206 & 2.978 & 0.084 & $1.269(0.968-1.663)$ \\
\hline
\end{tabular}

OR, odds ratio; CI, confidence interval; df, degree of freedom; HWE, Hardy-Weinberg equilibrium.

Table III. Distribution of genotypes and alleles according to age.

\begin{tabular}{|c|c|c|c|c|c|c|c|c|c|c|c|}
\hline \multirow[b]{2}{*}{ Age (years) } & \multicolumn{3}{|c|}{ Genotype (n) } & \multirow[b]{2}{*}{$\chi^{2}$} & \multirow{2}{*}{$\begin{array}{c}\text { P-value } \\
(\mathrm{df}=2)\end{array}$} & \multirow[b]{2}{*}{ HWE } & \multicolumn{2}{|c|}{ Allele (n) } & \multirow[b]{2}{*}{$\chi^{2}$} & \multirow{2}{*}{$\begin{array}{l}\text { P-value } \\
(\mathrm{df}=1)\end{array}$} & \multirow[b]{2}{*}{ OR $(95 \% \mathrm{CI})$} \\
\hline & GG & $\mathrm{AG}$ & AA & & & & G & A & & & \\
\hline \multicolumn{12}{|l|}{$\leq 55$} \\
\hline Cases $(n=166)$ & 70 & 79 & 17 & & & 0.494 & 219 & 113 & & & \\
\hline Controls $(n=224)$ & 87 & 108 & 29 & 0.862 & 0.650 & 0.667 & 282 & 166 & 0.756 & 0.385 & $1.141(0.848-1.536)$ \\
\hline \multicolumn{12}{|l|}{$55-65$} \\
\hline Cases $(n=244)$ & 99 & 113 & 32 & & & 1.000 & 311 & 177 & & & \\
\hline Controls $(n=243)$ & 95 & 113 & 35 & 0.215 & 0.898 & 0.892 & 303 & 183 & 0.200 & 0.655 & $1.061(0.818-1.377)$ \\
\hline \multicolumn{12}{|l|}{$\geq 65$} \\
\hline Cases $(n=311)$ & 143 & 144 & 24 & & & 0.148 & 430 & 192 & & & \\
\hline Controls $(n=164)$ & 74 & 70 & 20 & 2.654 & 0.265 & 0.601 & 218 & 110 & 0.705 & 0.401 & $1.130(0.849-1.503)$ \\
\hline
\end{tabular}

OR, odds ratio; CI, confidence interval; df, degree of freedom; HWE, Hardy-Weinberg equilibrium.

Table IV. Genotyping under dominant and recessive models.

\begin{tabular}{|c|c|c|c|c|c|c|c|c|}
\hline rs12619285 & $\begin{array}{c}\text { Dominant } \\
(\mathrm{GG} / \mathrm{AG}+\mathrm{AA})\end{array}$ & $\chi^{2}$ & $\begin{array}{l}\text { P-value } \\
(\mathrm{df}=1)\end{array}$ & OR $(95 \% \mathrm{CI})$ & $\begin{array}{c}\text { Recessive } \\
(\mathrm{GG}+\mathrm{AG} / \mathrm{AA})\end{array}$ & $\chi^{2}$ & $\begin{array}{c}\text { P-value } \\
(\mathrm{df}=1)\end{array}$ & OR $(95 \% \mathrm{CI})$ \\
\hline Total cases & $312 / 409$ & & & & $648 / 73$ & & & \\
\hline Total controls & $256 / 375$ & 1.009 & 0.315 & $1.117(0.900-1.388)$ & $547 / 84$ & 3.330 & 0.068 & $1.363(0.977-1.903)$ \\
\hline Male cases & $217 / 299$ & & & & $459 / 57$ & & & \\
\hline Male controls & $140 / 205$ & 0.185 & 0.667 & $1.063(0.806-1.402)$ & $297 / 48$ & 1.587 & 0.208 & $1.301(0.863-1.963)$ \\
\hline Female cases & $95 / 110$ & & & & $189 / 16$ & & & \\
\hline Female controls & $116 / 170$ & 1.629 & 0.202 & $1.266(0.881-1.818)$ & $250 / 36$ & 2.884 & 0.090 & $1.701(0.916-3.157)$ \\
\hline
\end{tabular}

OR, odds ratio; CI, confidence interval; df, degree of freedom.

Module (Applied Biosystems Life Technologies, Foster City, CA, USA). Subsequently, melting curve analysis was performed using a Roche LightCycler $480^{\circledR}$ fluorescence quantitative PCR instrument (Roche Diagnostics, Basel, Switzerland). The melting curve analysis program was $95^{\circ} \mathrm{C}$ for $15 \mathrm{sec}, 60^{\circ} \mathrm{C}$ for $30 \mathrm{sec}$, followed by increasing the temperature by $0.11^{\circ} \mathrm{C}$ per sec, until a temperature of $95^{\circ} \mathrm{C}$ was reached. As shown in
Fig. 1, the data of the melting curve analysis was obtained by clustering the fluorescence intensity analysis (25).

Statistical analysis. HWE analysis was performed using Arlequin software (version 3.5; Zoological Institute, University of Bern, Bern, Switzerland) (26). Differences in the genotype and allele frequencies between the case and control groups were 
calculated using CLUMP 22 software (Institute of Psychiatry, Denmark Hill, London, UK) with 10,000 Monte Carlo simulations (27). OR and 95\% CI values were determined using an online program (http://faculty.vassar.edu/lowry/odds $2 \times 2$. html). The Cochran-Mantel-Haenszel (CMH) test was performed using SAS 9.2 software (SAS Institute, Marlow, UK), while power analysis was conducted using the software of Power and Sample Size Calculation (version 3.0.43; Department of Biostatistics, Vanderbilt University, Nashville, TN, USA) (28). A two-tailed P-value of $<0.05$ was considered to indicate a statistically significant difference.

\section{Results}

Distribution of genotypes and alleles in the case and control groups. In total, $721 \mathrm{CHD}$ cases and 631 controls were recruited for the study in order to evaluate the contribution of the IKZF2 rs12619285 polymorphism to CHD. Genotype distributions of the IKZF2 rs12619285 polymorphism were shown to not deviate from the HWE in the CHD cases, non-CHD controls and additional subgroups divided by gender or age $(\mathrm{P}>0.05$; Tables I, II and III). The results did not reveal a statistically significant association between the rs12619285 polymorphism and CHD in the case-control study ( $\mathrm{P}=0.17$; OR, $1.139,95 \% \mathrm{CI}$, 0.972-1.334; Table I).

Associations with age and gender. Since the development of CHD may be involved with the interaction between genovariation and the environment (29), the samples were divided into subgroups according to age and gender $(30,31)$, from which subgroup association tests were performed. Subgroup analysis by gender did not identify an association between the rs12619285 polymorphism and CHD in males $(\mathrm{P}=0.356$; $\mathrm{OR}$, 1.099, 95\% CI, 0.899-1.344; Table II) or females ( $\mathrm{P}=0.084$; OR, 1.269, 95\% CI, 0.968-1.663). In addition, an association was not identified between rs12619285 and CHD in the breakdown analysis by age $(\mathrm{P}>0.05$; Table III).

Associations with genetic models and the severity of $C H D$. Association tests were also performed using dominant and recessive genetic models. However, no statistically significant difference in the distribution of rs12619285 genotypes or alleles were identified between the case and control subjects ( $\mathrm{P}>0.05$; Table IV). In addition, $\mathrm{CMH}$ statistical analysis was performed to investigate the association between rs12619285 and the number of arteries with stenosis in the CHD patients. Similarly, no statistically significant association was identified between the rs12619285 polymorphism and the severity of CHD ( $P>0.05$; data not shown). In addition, the $\mathrm{G}$ allele frequency was found to be $63.6 \%$ in the Han Chinese population, which was similar to the previous preliminary study where the G allele frequency was $62.8 \%$ (22). The power of the present case-control study was $63.3 \%$.

\section{Discussion}

In the present case-control study, a statistically significant association between $I K Z F 2$ rs12619285 and CHD was not identified, although there was a borderline statistical difference between the CHD cases and non-CHD controls in the female subgroup
$(\mathrm{P}=0.08)$. The case-control study included 1,352 individuals that comprised $721 \mathrm{CHD}$ cases and 631 controls. However, the current study was relatively small compared with a previous genome-wide association study that included 12,118 European and 5,212 East Asian individuals (21). Insufficient sample size may explain the negative association observed in the present study (statistical power, 63.3\%).

Further analysis indicated that there was an ethnic difference in the allele frequency of the $I K Z F 2$ rs12619285 polymorphism. The $\mathrm{G}$ allele frequency of rs12619285 in the HapMap European population was found to be $24.3 \%$, which was much smaller compared with that of the HapMap Han Chinese in Beijing (CHB) population (59.3\%). In addition, the $\mathrm{G}$ allele frequency was $63.6 \%$ in the controls of the present study, which was similar to that of the HapMap-CHB (59.3\%) population (32). The discrepancy in the allele frequency may help to explain why the present study failed to confirm the previously identified positive association between the IKZF2 rs12619285 polymorphism and $\mathrm{CHD}$ in the Han Chinese population.

Genetic heterogeneity may be an additional explanation for the negative results. A total of 3,355 polymorphisms have been identified in the $I K Z F 2$ gene. The current study only focused on one polymorphism of the $I K Z F 2$ gene; thus, the function of the $I K Z F 2$ gene may not be fully demonstrated. Future studies should investigate a greater number of polymorphisms in order to improve the understanding of the role of the $I K Z F 2$ gene in the susceptibility of CHD.

IKZF2 protein has been identified at an early phase of development in thymocytes; thus, IKZF2 has been regarded as a key regulator in lymphocyte differentiation (9). In addition, $I K Z F 2$ has been demonstrated to be involved in the earliest hematopoietic differentiation of human embryonic stem cells (33), and neutrophils and eosinophils are developed from hematopoietic progenitors (11). Eosinophils participate in the production and reproduction of inflammation (21), which may promote the development of CHD $(34,35)$. Thus, it was hypothesized that the $I K Z F 2$ gene may play a role in the pathogenesis of CHD.

In conclusion, the present case-control study demonstrated a lack of association between the IKZF2 rs12619285 polymorphism and CHD in the Han Chinese population. This observation indicated that other $I K Z F 2$ polymorphisms or different genes can affect the variation in blood eosinophil numbers, which may further the understanding into the contribution of inflammatory pathways in CHD.

\section{Acknowledgements}

The study was supported by grants from the National Natural Science Foundation of China (nos. 31100919 and 81371469), the Natural Science Foundation of Zhejiang Province (no. LR13H020003), the K.C. Wong Magna Fund in Ningbo University and the Ningbo Social Development Research Projects (no. 2012C50032).

\section{References}

1. Lopez AD, Mathers CD, Ezzati M, Jamison DT and Murray CJ: Global and regional burden of disease and risk factors, 2001: systematic analysis of population health data. Lancet 367 : $1747-1757,2006$. 
2. Mathers CD and Loncar D: Projections of global mortality and burden of disease from 2002 to 2030. PLoS Med 3: e442, 2006.

3. Libby P: Inflammation in atherosclerosis. Nature 420: 868-874, 2002.

4. Kroupis C, Theodorou M, Chaidaroglou A, et al: The association between a common FCGR2A polymorphism and C-reactive protein and coronary artery disease revisited. Genet Test Mol Biomarkers 14: 839-846, 2010.

5. Samani NJ, Erdmann J, Hall AS, et al; WTCCC and the Cardiogenics Consortium: Genomewide association analysis of coronary artery disease. N Engl J Med 357: 443-453, 2007.

6. Mangino $M$ and Spector T: Understanding coronary artery disease using twin studies. Heart 99: 373-375, 2013

7. Dai J, Krasnow RE, Liu L, Sawada SG and Reed T: The association between postload plasma glucose levels and 38-year mortality risk of coronary heart disease: the prospective NHLB Twin Study. PLoS One 8: e69332, 2013.

8. Vaccarino V, Goldberg J, Rooks C, et al: Post-traumatic stress disorder and incidence of coronary heart disease: a twin study. J Am Coll Cardiol 62: 970-978, 2013.

9. Georgopoulos K, Winandy S and Avitahl N: The role of the Ikaros gene in lymphocyte development and homeostasis. Annu Rev Immunol 15: 155-176, 1997.

10. Kelley CM, Ikeda T, Koipally J, et al: Helios, a novel dimerization partner of Ikaros expressed in the earliest hematopoietic progenitors. Curr Biol: CB 8: 508-515, 1998.

11. Chio KD, Vodyanik M and Slukvin II: Hematopoietic differentiation and production of mature myeloid cells from human pluripotent stem cells. Nat Protoc 6: 296-313, 2011.

12. Engelmann MG, Kolbe T, Faul C and Steinbeck G: Hypereosinophilic syndrome associated with heterozygous factor $\mathrm{V}$ gene mutation: an unusual combination resulting in an acute coronary syndrome and recurrent cerebral stroke - a case report. Angiology 55: 221-225, 2004.

13. Buysschaert ID, Grulois V, Eloy P, et al: Genetic evidence for a role of IL33 in nasal polyposis. Allergy 65: 616-622, 2010.

14. Akhabir L and Sandford A: Genetics of interleukin 1 receptor-like 1 in immune and inflammatory diseases. Curr Genomics 11: 591-606, 2010

15. Sekkach Y, Mekouar F, Jira M, et al: Durable efficacity and remission after treatment with imatinib mesylate for FIP1L1-PDGFRA transcript negative associated eosinophilic cardiomyopathy. Ann Pharm Fr 69: 277-281, 2011 (In French).

16. Singh RK, Gupta S, Dastidar S and Ray A: Cysteinyl leukotrienes and their receptors: molecular and functional characteristics. Pharmacology 85: 336-349, 2010.

17. Hogan SP, Rosenberg HF, Moqbel R, et al: Eosinophils: biological properties and role in health and disease. Clin Exp Allergy 38: 709-750, 2008

18. Roivainen M, Viik-Kajander M, Palosuo T, et al: Infections, inflammation, and the risk of coronary heart disease. Circulation 101: 252-257, 2000.

19. Sato Y, Fukunaga T, Hayashi T and Asada Y: Hypereosinophilic syndrome associated with occlusive coronary thrombosis and right ventricular thrombus. Pathol Int 58: 138-141, 2008.
20. Sakai T, Inoue S, Matsuyama TA, et al: Eosinophils may be involved in thrombus growth in acute coronary syndrome. Int Heart J 50: 267-277, 2009.

21. Gudbjartsson DF, Bjornsdottir US, Halapi E, et al: Sequence variants affecting eosinophil numbers associate with asthma and myocardial infarction. Nat Genet 41: 342-347, 2009.

22. Lian J, Huang Y, Huang RS, et al: Meta-analyses of four eosinophil related gene variants in coronary heart disease. J Thromb Thrombolysis 36: 394-401, 2013.

23. No authors listed: Nomenclature and criteria for diagnosis of ischemic heart disease. Report of the Joint International Society and Federation of Cardiology/World Health Organization task force on standardization of clinical nomenclature. Circulation 59: 607-609, 1979

24. Wang J, Chuang K, Ahluwalia M, et al: High-throughput SNP genotyping by single-tube PCR with Tm-shift primers. Biotechniques 39: 885-893, 2005.

25. Yuan F, Xu J, Ji LD, et al: Application of Tm-shift genotyping method in genetic studies. Yi Chuan 34: 1484-1490, 2012 (In Chinese).

26. Excoffier L and Lischer HE: Arlequin suite ver 3.5: a new series of programs to perform population genetics analyses under Linux and Windows. Mol Ecol Resour 10: 564-567, 2010.

27. Sham PC and Curtis D: Monte Carlo tests for associations between disease and alleles at highly polymorphic loci. Ann Hum Genet 59: 97-105, 1995.

28. Dupont WD and Plummer WD Jr: Power and sample size calculations. A review and computer program. Control Clin Trials 11: $116-128,1990$

29. Liu H, Huang XQ, Yang M, et al: MRAS genetic variation is associated with atherothrombotic stroke in the Han Chinese population. J Clin Neurol 9: 223-230, 2013.

30. Li X, He M, Zhu J, Yao P, Li X, Yuan J, Min X, Lang M, Yang H, $\mathrm{Hu}$ FB, Wu T and Wei S: Higher carbohydrate antigen 125 levels are associated with increased risk of coronary heart disease in elderly chinese: a population-based case-control study. PLoS One 8: e81328, 2013.

31. Jiang D, Zheng D, Wang L, et al: Elevated PLA2G7 gene promoter methylation as a gender-specific marker of aging increases the risk of coronary heart disease in females. PLoS One 8: e59752, 2013.

32. National Center for Biotechnology Information: HapMap population allele frequency data. http://www.ncbi.nlm.nih.gov. Accessed February 7,2014.

33. Halsell SR and Kiehart DP: Second-site noncomplementation identifies genomic regions required for Drosophila nonmuscle myosin function during morphogenesis. Genetics 148: 1845-1863, 1998.

34. Jia LX, Qi GM, Liu O, Li TT, Yang M, Cui W, Zhang WM, Qi YF and Du J: Inhibition of platelet activation by clopidogrel prevents hypertension-induced cardiac inflammation and fibrosis. Cardiovasc Drugs Ther 27: 521-530, 2013.

35. Paoletti R, Gotto AM Jr and Hajjar DP: Inflammation in atherosclerosis and implications for therapy. Circulation 109 (23 Suppl 1): III20-III26, 2004. 